\title{
Genetic analysis of calf and heifer losses in Danish Holstein
}

\author{
B. Fuerst-Walt|* and M. K. Sørensen†‡ \\ *University of Natural Resources and Applied Life Sciences Vienna, Department of Sustainable Agricultural Systems, Division of Livestock \\ Sciences, Gregor Mendel-Str. 33, A-1180 Vienna, Austria \\ †University of Aarhus, Faculty of Agricultural Sciences, Department of Genetics and Biotechnology, PO Box 50, DK-8830 Tjele, Denmark \\ ‡Danish Agricultural Advisory Service, Udkaersvej 15, Skejby, 8200 Aarhus N, Denmark
}

\begin{abstract}
Mortality in dairy cattle is not only relevant with regard to economic losses but also to animal health and welfare. Thus, the aim of this investigation was to explore the genetic background of postnatal mortality in calves and replacement heifers in different age groups until first calving in Danish Holsteins. Records of Danish Holstein heifer calves born in the years 1998 to 2007 were extracted from the Danish Cattle database (Danish Cattle, Skejby, Denmark). The following periods (P) were defined for analyses: $\mathrm{P} 1=\mathrm{d} 1$ to $30, \mathrm{P} 2=\mathrm{d} 31$ to $180, \mathrm{P} 3=\mathrm{d} 181$ to $365, \mathrm{P} 4=\mathrm{d} 366$ until the day before first calving or a maximum age of $1,200 \mathrm{~d}$ if no calving was reported, and the full period $\mathrm{P} 5=\mathrm{d} 1$ until the day before first calving or a maximum age of 1,200 d if no calving was reported. Records of animals slaughtered or exported within a defined period were set to missing for this and following periods, whereas their records were kept for preceding periods. After further data editing, more than 840,000 calves and heifers born in the years 1998 to 2007 were investigated. Mortality rates were $3.23,2.66,0.97,1.92$, and $9.36 \%$ for the defined periods $\mathrm{P} 1$ to P5, respectively. For the estimation of genetic parameters, linear and threshold sire models were applied. Effects accounted for were the random effects herd $x$ year $\times$ season and sire as well as the fixed effects year $\times$ month, number of dam's parity (parities $>5$ were set to 5), calf size, and calving ease. In total, the pedigree consisted of 4,643 sires and 20,821 animals. Heritabilities for the linear model were low, ranging from 0.006 (P3) to 0.042 (P5). Heritabilities estimated by threshold models showed a wider range, from not significantly different from zero for periods with low frequencies to 0.082 for P1. The mortality rate until first calving was higher than the stillbirth rate. Genetic and phenotypic variation seemed to be sufficiently high to genetically improve the trait calf and heifer mortality. Hence, a routine genetic evaluation would be valuable for moni-
\end{abstract}

Received March 4, 2010.

Accepted July 5, 2010.

${ }^{1}$ Corresponding author: birgit.fuerst-waltl@boku.ac.at toring and for selecting fitter animals in the Danish Holstein cattle population.

Key words: Holstein calf, heifer, genetic parameter, mortality

\section{INTRODUCTION}

In dairy breeds, mortality rates of cows (e.g., McConnel et al., 2008) and stillbirth (Hansen et al., 2004) have increased during recent years. Evidence also suggests increased postnatal mortality rates in Danish Jersey (Norberg, 2008). This is relevant with regard not only to animal health and welfare but also to economic losses. For Scandinavian countries, Østerås et al. (2007) calculated the annual total losses due to dairy calf mortality (including those born dead) to be approximately $€ 70$ million. For the United Kingdom, calf losses were estimated at a cost to the industry of about $£ 60$ million (Defra, 2003) per annum. However, only deaths until $180 \mathrm{~d}$ postpartum were considered in these calculations. Losses at higher ages up to first calving are even more economically important than early losses because rearing costs increase with age. Higher female calf or heifer mortality also results in reduced possibility for selection and hence reduced genetic gain.

Although genetic evaluations exist for stillbirth and longevity in cows in many countries worldwide (www. interbull.org), to our knowledge no breeding values are available for losses of replacement animals. In the European Union, information about survival is generally available because of the obligatory cattle registration (EC Regulation No. 1760/2000); still, there is an almost complete lack of knowledge with respect to the genetic background of heifer survival between 24 or 48 $\mathrm{h}$ and the start of productive life. Among studies in calf survival are those in Danish Holsteins (Hansen et al., 2003), reporting 6.6\% (both sexes) and in Danish Jerseys (Norberg, 2008) reporting 12.5\% (females only) of calves dying until an age of $180 \mathrm{~d}$. In Norway, Gulliksen et al. (2009) reported a mortality rate of $3.7 \%$ in the first year of life in Norwegian dairy herds, and Svensson et al. (2006) observed 3.1\% of calves dying up to an age of $90 \mathrm{~d}$ in southwestern Swedish farms. In the 
United Kingdom, up to $6 \%$ of calves are estimated to die before they reach 6 mo of age (Defra, 2003; OrtizPelaez et al., 2008), and in the United States, mortality rates of 7.8 and $1.8 \%$ of unweaned and weaned dairy heifers, respectively, are reported (USDA, 2007). However, in most of these studies only losses up to the age of $1 \mathrm{yr}$ are covered. Heritability estimates for losses of calves and replacement animals are also scarce. For losses during the first week of life in Brown Swiss calves, heritabilities of 0.008 (estimated by REML) and 0.04 (adjusted for binary traits) were reported (Erf et al., 1990). In the Danish studies by Hansen et al. (2003) and Norberg (2008), heritabilities were estimated for calf losses up to an age of $180 \mathrm{~d}$ and ranged from $<0.01$ to 0.03 . No estimates are available, however, for heifer losses or losses in the total replacement period.

In a review, Shook (1998) concluded that more genetic studies of calfhood diseases and mortality were needed. Extensive knowledge and analysis of the genetics of juvenile survival are valuable for better understanding the biological background, monitoring cattle populations, and perhaps for providing a basis for selection. Thus, the aim of this investigation was to explore the genetic background of postnatal mortality in calves and replacement heifers in the Danish Holstein population in 5 periods using linear and threshold sire models. Furthermore, breeding values and genetic trends were estimated.

\section{MATERIALS AND METHODS}

\section{Animals}

Records of 1,814,801 Danish Holstein heifer calves born in the years 1998 to 2007 that survived the first $24 \mathrm{~h}$ after birth were extracted from the Danish Cattle database (Danish Cattle, Skejby, Denmark). Only calves with known sires were extracted. Furthermore, data were restricted to animals with complete life and calving history, single-born calves, no transfer between herds, heifers with an age at first calving in the interval from 550 to 1,200 d, calves born with registration on calf size when born, and calves with registration on calving ease. Animals that were slaughtered or exported within a defined period and those too young to theoretically reach the maximum age of the respective period were set to missing for this and following periods, while their records were kept for preceding periods. After that, data were restricted to herds with a minimum of 30 records per herd-year and sires with a minimum of 30 offspring. These restrictions were responsible for the major reduction in data. In total, records of 843,774 calves and heifers sired by 4,643 bulls were investigated. Data preparation and descriptive statistics were carried out by means of the software package SAS 9.2 (SAS Institute, 2008).

\section{Definition of Traits}

Evidence from an earlier study (Hansen et al., 2003) suggests that survival of calves and heifers is different at various stages of life and may therefore be controlled by dissimilar genes. To analyze survival data of juvenile cattle, the following periods $(\mathbf{P})$ were defined: $\mathrm{d} 1$ to 30 (P1), d 31 to 180 (P2), d 181 to 365 (P3), d 366 to the day before first calving (a maximum of 1,200 d, P4). Additionally, the full period between $1 \mathrm{~d}$ after birth and the day before first calving was defined as P5. Periods 1 and 2 correspond to neonatal and calf mortality as defined by Wathes et al. (2008), with calves dying between $24 \mathrm{~h}$ and $28 \mathrm{~d}$ and between 1 and $6 \mathrm{mo}$ of life, respectively. The calves and heifers were scored as 1 if they died within the respective period and 0 otherwise, resulting in a binary data structure.

\section{Statistical Analysis}

In previous genetic analyses of calf mortality within the first $180 \mathrm{~d}$ of life, those binary traits were analyzed with linear rather than threshold models (Hansen et al., 2003; Norberg, 2008) although threshold models could result in more accurate estimates of variance components (Gianola and Foulley, 1983). The main reasons for using linear instead of threshold models are that (1) they are generally less computationally demanding, and (2) predicted breeding values were shown to be highly correlated to those estimated using binary models in previous studies (e.g., Carlén et al., 2006). Furthermore, genetic correlations are reported to be correct for binary traits using linear models (Heringstad et al., 2005; Negussie et al., 2008). For this analysis, both methodologies - a linear and a threshold sire model - were applied. The pedigree of the 4,643 sires was traced in the Nordic pedigree file, and consisted of 20,821 animals.

Linear Sire Model. Variance components were estimated in univariate and bivariate linear sire models using the average information REML procedure (Jensen et al., 1997) as implemented in the DMU software (Madsen and Jensen, 2006). Effects included in the models were as follows:

$$
\begin{aligned}
\mathrm{Y}_{\mathrm{ijklmno}} & =\text { hys }_{\mathrm{i}}+\mathrm{YM}_{\mathrm{j}}+\text { Parity }_{\mathrm{k}}+\text { Ease }_{\mathrm{l}} \\
& + \text { Size }_{\mathrm{m}}+\text { sire }_{\mathrm{n}}+\varepsilon_{\mathrm{ijklmno}}
\end{aligned}
$$

where $Y_{\mathrm{ijklmno}}=$ individual observation of mortality in $\mathrm{P} 1$ to $\mathrm{P} 5$; hys $_{\mathrm{i}}=$ the random effect of herd $\times$ year 
Table 1. Number of observations (n), mortality (\%) in different periods, and mean, median, and $25 \%$ quartile for heifers that died

\begin{tabular}{|c|c|c|c|c|c|}
\hline \multirow[b]{2}{*}{ Period $^{1}$} & \multirow[b]{2}{*}{$\mathrm{n}$} & \multirow[b]{2}{*}{$\begin{array}{c}\text { Mortality } \\
(\%)\end{array}$} & \multicolumn{3}{|c|}{ Age of heifers that died (d) } \\
\hline & & & $\begin{array}{l}\text { Mean } \\
\text { (SD) }\end{array}$ & Median & $\begin{array}{c}\text { Quartile } \\
(25 \%)\end{array}$ \\
\hline P1 & 843,774 & 3.23 & $12.2(6.8)$ & 11 & 7 \\
\hline P2 & 794,472 & 2.66 & $89.2(41.8)$ & 82 & 53 \\
\hline P3 & 729,198 & 0.97 & $258.4(53.2)$ & 250 & 211 \\
\hline $\mathrm{P} 4$ & 474,904 & 1.92 & $679.8(195.2)$ & 680 & 512 \\
\hline P5 & 513,868 & 9.36 & $189.9(263.6)$ & 65 & 13 \\
\hline
\end{tabular}

$\times$ season i $($ herd $=1, \ldots, 3,099 ;$ year $=1998, \ldots, 2007$; season $=1, \ldots, 4) ; \mathrm{YM}_{\mathrm{j}}=$ the fixed effect of year $\times$ month j; Parity ${ }_{\mathrm{k}}=$ the fixed effect of the dam's parity $\mathrm{k}$ $(\mathrm{k}=1, \ldots, 5$ with parities $>5$ set to 5$) ;$ Ease $_{1}=$ the fixed effect of calving ease $1(1=1, \ldots, 4 ; 1=$ easy calving, 2 $=$ below average, $3=$ above average, $4=$ difficult and caesarean); Size $_{\mathrm{m}}=$ the fixed effect of calf size $\mathrm{m}(\mathrm{m}$ $=1, \ldots, 4 ; 1=$ small, $2=$ below average, $3=$ above average, $4=$ large); sire $_{n}=$ the random genetic effect of sire $\mathrm{n}(\mathrm{n}=1, \ldots, 4,643)$; and $\varepsilon_{\mathrm{ijklmno}}=$ the random residual.

Threshold Sire Model. Mortality in all periods was analyzed separately using a threshold model (Gianola and Foulley, 1983) that accounted for the binary $(0,1)$ nature of the data. The same software package DMU (Madsen and Jensen, 2006), with a working algorithm based on generalized linear mixed models, was used for threshold model analyses. Generalized linear mixed models are based on finding a relationship (link function) between the expected value of a random variable and a linear function of explanatory variables (Tempelman, 1998; Kachman, 2000). Variance components were estimated by applying the binomial distribution with a logit link function. In matrix notation, the threshold model was as follows:

$$
\boldsymbol{\lambda}=\mathbf{X} \boldsymbol{\beta}+\mathbf{Z}_{\mathbf{h}} \mathbf{h}+\mathbf{Z}_{\mathbf{s}} \mathbf{s}+\mathbf{e},
$$

where $\boldsymbol{\lambda}$ is a vector of unobserved liabilities to mortality; $\boldsymbol{\beta}$ is a vector of systematic effects (including the same fixed effects as in the linear model mentioned above); $\mathbf{h}$ is a vector of random herd-year-season of calving effects (as above); $\mathbf{s}$ is a vector of sire effects; $\mathbf{e}$ is a vector of residuals; and $\mathbf{X}, \mathbf{Z}_{\mathbf{h}}$, and $\mathbf{Z}_{\mathrm{s}}$ are the corresponding incidence matrices. The well-known extreme category problem (i.e., all observations in individual subclasses are either 0 or 1 ) of the threshold model, that occurs especially in traits with low incidences, was alleviated by treating the herd-year-season effect as random (Sorensen and Gianola, 2002). Heritabilities were calculated using the variance of the logit link function, which implies a residual variance of $\pi^{2} / 3$ (Southey et al., 2003).

\section{Genetic Evaluation}

For the estimation of breeding values, the software package DMU (Madsen and Jensen, 2006) was used. Relative breeding values were calculated for all sires by transforming to a mean of 100 and a standard deviation of 10 points with base animals consisting of 7 - to 9 -yr-old bulls and positive values being desirable. For inclusion in genetic trends, sires needed a minimum of 100 offspring. For the same sires, Pearson correlations between breeding values estimated by means of linear and threshold models, respectively, were estimated using the software package SAS 9.2 (SAS Institute, 2008).

\section{RESULTS AND DISCUSSION}

\section{Heifer Mortality}

During the first month of life, the mortality of the analyzed 843,774 Danish Holstein heifer calves was $3.23 \%$ (Table 1). In British Holsteins, a corresponding value of $3.4 \%$ was reported (Brickell et al., 2007). In an earlier study, Hansen et al. (2003) analyzed the first $14 \mathrm{~d}$ of life in Danish Holstein heifers and calculated a mortality of $2.4 \%$. For US Brown Swiss heifer calves (Erf et al., 1990), a mortality of $2.56 \%$ was reported for d 1 to 7; however, the data set was rather small. Of all heifer calves dying within P1 in this study, $25 \%$ died within the first week of life.

In later periods ( $\mathrm{P} 2, \mathrm{P} 3$, and $\mathrm{P} 4)$, mortality rates were lower, being $2.66,0.97$, and $1.92 \%$, respectively (Table 1). The mortality until $180 \mathrm{~d}$ (P1 plus P2) was comparable to that reported by Hansen et al. (2003) for female calves in the same population. However, the overall mortality of calves, male and female, was higher in the latter study as the authors reported a mortality 
Table 2. Variance $\left(\sigma^{2}\right)$ components (hys $=$ herd $\times$ year $\times$ season, res $=$ residual) \pm standard errors estimated for calf and heifer mortality in different periods)

\begin{tabular}{|c|c|c|c|c|c|}
\hline Period $^{1}$ & \multicolumn{3}{|c|}{ Linear model } & \multicolumn{2}{|c|}{ Threshold model $^{2}$} \\
\hline P2 & $0.0009 \pm<0.0001$ & $0.0001 \pm<0.0001$ & $0.0249 \pm<0.0001$ & $<0.0001 \pm 0.0060$ & $<0.0001 \pm 0.0001$ \\
\hline P3 & $0.0002 \pm 0.0005$ & $<0.0001 \pm<0.0001$ & $0.0094 \pm<0.0001$ & $<0.0001 \pm 0.0141$ & $<0.0001 \pm 0.0002$ \\
\hline $\mathrm{P} 4$ & $0.0005 \pm<0.0001$ & $<0.0001 \pm<0.0001$ & $0.0183 \pm<0.0001$ & $<0.0001 \pm 0.0128$ & $<0.0001 \pm 0.0003$ \\
\hline P5 & $0.0051 \pm<0.0001$ & $0.0009 \pm<0.0001$ & $0.0789 \pm 0.0002$ & $0.4968 \pm 0.0099$ & $0.0731 \pm 0.0074$ \\
\hline
\end{tabular}

${ }^{1} \mathrm{P} 1=\mathrm{d} 1-30 ; \mathrm{P} 2=\mathrm{d}$ 31-180; P3 = d 181-365; P4 = d 366 to day before first calving; and P5 = d 1 to day before first calving.

${ }^{2}$ Residual variance $=1$, for calculation of heritabilities correction of the residual variance by the factor $\pi^{2} / 3$.

of $7.78 \%$ until $180 \mathrm{~d}$ in male calves, whereas only $5.60 \%$ of females died in the same period, which is in agreement with the present results including 3 yr of extra data. Erf et al. (1990) also observed a higher mortality of male compared with female Brown Swiss calves during the first week of life. Generally, it should be realized that published mortality rates may be underestimated in several cases because, for example, twins and multiples or animals with incomplete information are mostly excluded from analyses.

Of 513,868 heifers that were not exported or slaughtered or too young to be considered in the analysis, 9.36\% died from d 1 until the day before first calving. The mean age that heifers died was $189.9 \pm 263.6 \mathrm{~d}$. The $10 \%$ and $25 \%$ quartiles were 8 and $13 \mathrm{~d}$, respectively, with the median of $65 \mathrm{~d}$ (Table 1) confirming that the risk of calf mortality is highest during early stages of life. In Austrian Fleckvieh heifers (dual-purpose Simmental), mortality rates were distinctly lower for the period born alive to first calving $(5.61 \%$ for P5; Fuerst-Waltl and Fuerst, 2010), whereas in Danish Jersey heifers (Norberg, 2008), mortality was $12.5 \%$ up to an age of $180 \mathrm{~d}$. Wathes et al. (2008) reported a juvenile mortality rate (i.e., the mortality between 6 mo of age and the start of the service period at about $15 \mathrm{mo}$ ) of $3.5 \%$. However, the authors also included culled heifers. For comparison, the average stillbirth rate (born dead or died within $24 \mathrm{~h}$, both sexes) in Danish Holsteins in the year 2008 was $9.5 \%$ for first and $5.4 \%$ for second and higher calvings, respectively (Team Avlsværdivurdering Dansk Kvæg, 2009). Thus, the more costly mortality of replacement stock is, on average, higher than that of stillbirth.

\section{Variance Components and Genetic Parameters}

Estimates for variance components and heritabilities are given in Tables 2 and 3, respectively. Heritabilities for mortality in the different observed periods between born alive and first calving ranged from $0.006(\mathrm{P} 4)$ to 0.042 (P5) for the linear sire model (Table 3); that is, on the observable scale. Sire variances were found to be significantly different from zero for P1, P2, and P5 only. Heritabilities estimated by bivariate analyses were similar to those estimated by univariate analyses (data not shown). Maternal effects were not considered in the model because maternal heritabilities were shown to be $0.1 \%$ or lower and mostly nonsignificant in the earlier study of Hansen et al. (2003). Heritabilities for calf and heifer mortality in Danish Holstein were in accordance with those reported in Austrian Fleckvieh (Fuerst-Waltl and Fuerst, 2010), where the values for $\mathrm{P} 1$ and P2 were $<0.01$, whereas heritabilities in P3 and $\mathrm{P} 4$ did not significantly differ from zero. They are also in the range of previous studies in Brown Swiss (Erf et al., 1990), Danish Holstein (Hansen et al., 2003), and Jersey calves (Norberg, 2008) up to an age of $180 \mathrm{~d}$. Heritabilities estimated by threshold models were distinctly higher for $\mathrm{P} 1$ and $\mathrm{P} 5$, being 0.082 and 0.076 , respectively, whereas the values for P2 to $\mathrm{P} 4$ were $<0.001$ and not significantly different from zero (Table 3 ). The latter finding might have been caused by the lower frequencies in these periods. The adjustment for calf size and calving ease may have biased downward the genetic and the residual variances. Both effects were significant for P1, P2, and P5. The consequence of the adjustment is that the variance components were partly "cleaned" for the effects of calf size and calving ease.

Heritabilities, genetic SD, and genetic coefficients of variation $(\mathrm{CV})$ for $\mathrm{P} 1$ and $\mathrm{P} 5$ were sufficiently high for genetic improvement. For P1, these values were 0.017, $2.3 \%$, and 0.72 , respectively, using linear estimates. The corresponding estimates for P5 were $0.042,6.0 \%$, and 0.64 .

The genetic correlations between the different periods ranged from 0.49 (P1 to $\mathrm{P} 4$ ) to 0.92 (P2 to P3, Table 3). Generally, the genetic correlations between P1 and other periods were lowest, supporting an earlier study (Hansen et al., 2003) and indicating that different genes control mortality in the early and late postnatal stages. Because the frequencies and heritabilities for later postnatal mortality were rather low and the genetic cor- 
Table 3. Heritabilities $\left(\mathrm{h}^{2}\right.$ lin estimated by linear sire models, $\mathrm{h}_{\text {th }}^{2}$ estimated by threshold sire models $)$ and genetic correlations estimated for calf and heifer mortality in different periods

\begin{tabular}{llccccc}
\hline & \multicolumn{2}{c}{ Heritabilities } & & \multicolumn{3}{c}{ Genetic correlation $^{2}$} \\
\cline { 2 - 3 } \cline { 5 - 7 } Period $^{3}$ & $\mathrm{~h}^{2}{ }_{\text {lin }}$ & $\mathrm{h}_{\text {th }}{ }^{3}$ & & $\mathrm{P} 2$ & $\mathrm{P} 3$ & $\mathrm{P} 4$ \\
\hline P1 & 0.017 & 0.082 & & 0.60 & $-{ }^{4}$ & 0.49 \\
P2 & 0.022 & $<0.001$ & & & 0.92 & 0.71 \\
P3 & 0.009 & $<0.001$ & & & 0.81 \\
P4 & 0.006 & $<0.001$ & & & & \\
P5 & 0.042 & 0.076 & & & & \\
\hline
\end{tabular}

${ }^{1} \mathrm{P} 1=\mathrm{d} 1-30 ; \mathrm{P} 2=\mathrm{d} 31-180 ; \mathrm{P} 3=\mathrm{d} 181-365 ; \mathrm{P} 4=\mathrm{d} 366$ to day before first calving; and $\mathrm{P} 5=\mathrm{d} 1$ to day before first calving.

${ }^{2}$ Estimated by bivariate analyses and linear sire models.

${ }^{3}$ For calculation of heritabilities correction of the residual variance by the factor $\pi^{2} / 3$.

${ }^{4}$ Did not converge.

relations between periods were reasonably high, either 2 periods ( $\mathrm{P} 1$ and $\mathrm{P} 2+\mathrm{P} 3+\mathrm{P} 4)$ or the full period (P5) could be taken into account for future developments aimed at routine evaluations. The advantage of 2 periods is that a relatively small number of records are lost during the first $30 \mathrm{~d}$ due to export or slaughtering and that information on bulls is sooner available.

Modeling the genetic effects of the sire could have been done using survival analyses (Ducrocq and Sölkner, 1998). This assumes, however, a constant effect of sire and sire variance over time, which was not the case in the present study. Furthermore, the current number of sires presumably is beyond the limits for survival analyses.

\section{Breeding Values and Genetic Trend}

Genetic trends were calculated for P1 and P5, the periods with sire variances significantly different from zero. A significant but negligible positive trend was observed for P1 (Figure 1), whereas no clear genetic trend was found for P5 (Figure 2). In total, 916 and 324 bulls, respectively, with birth years 1990 to 2005 and a minimum of 100 records, were considered. The relatively small number of sires with more than 100 female offspring was due to the strict editing criteria. The relative average breeding values (positive values are desirable; mean $=100, \mathrm{SD}=10$; base animals are 5- to 7-yr-old bulls; that is, 236 and 86 bulls for P1 and P5, respectively) varied around 100 units and were almost identical for both estimation methods. The Spearman rank correlations for breeding values of these bulls estimated by linear and threshold models were 0.986 and 0.991 for $\mathrm{P} 1$ and $\mathrm{P} 5$, respectively. Thus, only small changes in ranking of bulls occurred depending on evaluation method. Rank correlations between P1 and P5 were 0.61 and 0.62 for the linear and the threshold model, respectively. For P1, the best bull based on the linear analysis ranked second in the threshold analysis, had 266 offspring and relative breeding values of 124 and 128. Two of his heifer calves $(0.75 \%)$ died in P1. The worst bull for P1 had 122 offspring in the data set, of which $24(20 \%)$ died in the same period. His breeding values were 38 and 53 for the linear and threshold model. For P5, the best bull based on the linear analysis had 249 offspring and a relative breeding value of 125 . He ranked fourth in the threshold analysis with a relative breeding value of 129 and an average mortality rate of $3.6 \%$. For P5, the worst bull was the same for both methods, having relative breeding values of 42 and 51 (linear and threshold, respectively) with a mortality rate of $30.7 \%$ of his 117 female offspring. Average reliabilities were 0.51 (0.29 to 0.95$)$ and 0.69 (0.43 to 0.95 ) for P1 and P5. Rank correlations between breeding values for $\mathrm{P} 1$ and the Nordic index for stillbirth at first calving (direct) were not significantly different

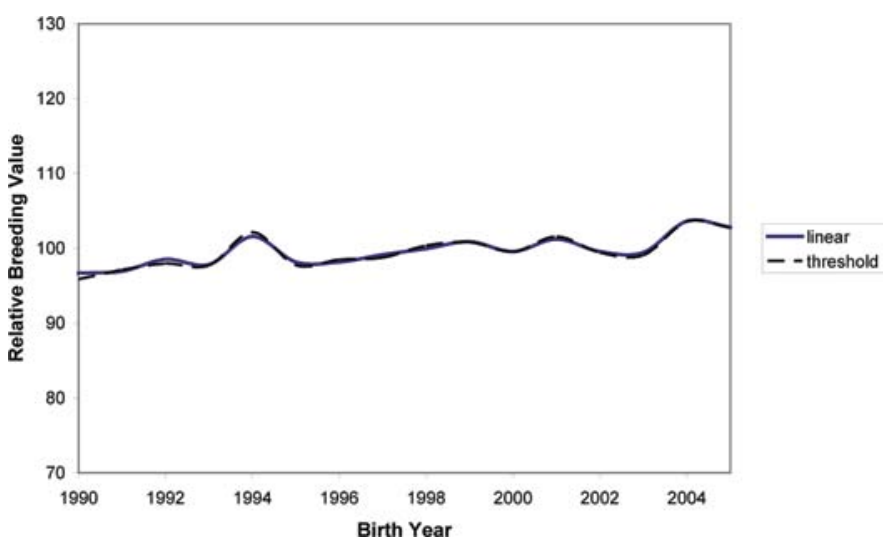

Figure 1. Genetic trend in breeding values for Danish Holstein bulls with a minimum of 100 records $(\mathrm{n}=916$, mean $=100, \mathrm{SD}=10$ points; positive values are desirable) for heifer mortality between $\mathrm{d} 1$ and 30 (period 1) using linear and threshold sire models. Color version available in the online PDF. 


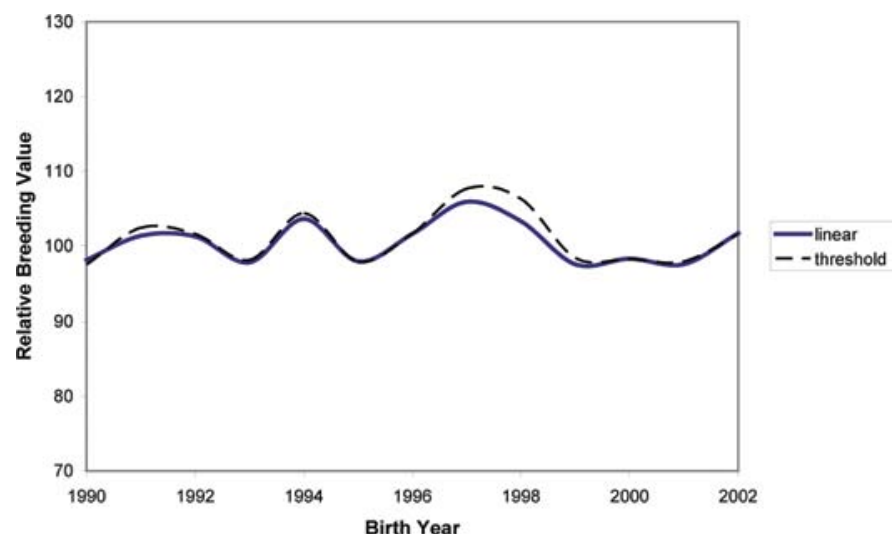

Figure 2. Genetic trend in breeding values for Danish Holstein bulls with a minimum of 100 records $(n=324$, mean $=100$, SD $=10$ points; positive values are desirable) for losses between $1 \mathrm{~d}$ after birth and day before first calving (period 5) using linear and threshold sire models. Color version available in the online PDF.

from zero. Correlations between the breeding values for P5 and the Nordic index for stillbirth at first calving (direct) were 0.09 (linear model) and 0.10 (threshold model). Among the reasons for these low correlations may be the fact that index for stillbirth includes both heifer and bull calves, the latter having the highest stillbirth rate. Rank correlations between the Nordic index for longevity and breeding values for P1 were between 0.05 and 0.06 for both linear and threshold breeding values. The correlations between the Nordic index for longevity and breeding values for P5 were favorable for both the breeding values based on linear and threshold breeding values with 0.22 and 0.24 , respectively.

\section{CONCLUSIONS}

Calf and heifer mortality is generally neglected in cattle breeding programs although genetic evaluations for stillbirth are common in many countries. In Danish Holstein, the mortality rate until first calving is higher than the stillbirth rate. Thus, this trait has both ethical and economic relevance. For P1 and P5, heritabilities, genetic SD, and genetic coefficients of variation seem to be sufficiently high for genetic improvement of calf and heifer mortality. Hence, a routine genetic evaluation would be valuable for both monitoring and for selecting fitter animals in the Danish Holstein cattle population.

\section{ACKNOWLEDGMENTS}

The authors wish to thank the Danish Cattle (Skejby, Denmark) for providing data and P. Madsen (University of Aarhus, Faculty of Agricultural Sciences, Department of Genetics and Biotechnology, Denmark) for many valuable discussions. Financial support of Birgit Fuerst-Waltl by the Austrian Science Foundation (FWF; Elise-Richter Program V43-B12) is gratefully acknowledged.

\section{REFERENCES}

Brickell, J. S., N. Bourne, and N. D. C. Wathes. 2007. The incidence of calf mortality on dairy farms in southern England. Proceedings of the British Society of Animal Science 2007. http://www.bsas. org.uk/downloads/annlproc/Pdf2007/pdf2007.pdf Accessed May $5,2010$.

Carlén, E., U. Emanuelson, and E. Strandberg. 2006. Genetic evaluation of mastitis in dairy cattle using linear models, threshold models, and survival analysis: A simulation study. J. Dairy Sci. 89:4049-4057.

Defra. 2003. Improving Calf Survival. http://www.defra.gov.uk/foodfarm/farmanimal/ welfare/onfarm/documents/calfsurv03.pdf Accessed May 5, 2010.

Ducrocq, V., and J. Sölkner. 1998. The survival kit-V3.0: A package for large analysis of survival data. Proc 6th World Congr. Genet. Appl. Livest. Prod. 27:445-446.

Erf, D. F., L. B. Hansen, and R. R. Neitzel. 1990. Inheritance of calf mortality for Brown Swiss cattle. J. Dairy Sci. 73:1130-1134.

Fuerst-Waltl, B., and C. Fuerst. 2010. Mortality in Austrian dualpurpose Fleckvieh calves and heifers. Livest. Sci. 132:80-86. doi:10.1016/j.livsci.2010.05.005.

Gianola, D., and F. L. Foulley. 1983. Sire evaluation for ordered categorical data with a threshold model. Genet. Sel. Evol. 15:201224 .

Gulliksen, S. M., K. I. Lie, T. Løken, and O. Østerås. 2009. Calf mortality in Norwegian dairy herds. J. Dairy Sci. 92:2782-2795.

Hansen, M., P. Madsen, J. Jensen, J. Pedersen, and L. G. Christensen. 2003. Genetic parameters of postnatal mortality in Danish Holstein calves. J. Dairy Sci. 86:1807-1817.

Hansen, M., I. Misztal, M. S. Lund, J. Pedersen, and L. G. Christensen. 2004. Undesired phenotypic and genetic trend for stillbirth in Danish Holsteins. J. Dairy Sci. 87:1477-1486.

Heringstad, B., Y. M. Chang, D. Gianola, and G. Klemetsdal. 2005. Genetic association between susceptibility to clinical mastitis and protein yield in Norwegian dairy cattle. J. Dairy Sci. 88:15091514.

Jensen, J., E. A. Mäntysaari, P. Madsen, and R. Thompson. 1997. Residual maximum likelihood estimation of (co) variance components in multivariate mixed linear models using average information. J. Ind. Soc. Agric. Stat. 49:215-236.

Kachman, S. D. 2000. An introduction to generalized linear mixed models. Pages 59-73 in Proc. Implementation Strategies for National Beef Cattle Evaluation. NCR Coordinating Committee Symposium, Athens, GA. http://statistics.unl.edu/faculty/steve/ glmm/paper.pdf Accessed August 12, 2010

Madsen, P., and J. Jensen. 2006. A user's guide to DMU. Version 6, release 4.6. Danish Institute of Agricultural Sciences, Research Centre Foulum, Denmark.

McConnel, C. S., J. E. Lombard, B. A. Wagner, and F. B. Garry. 2008. Evaluation of factors associated with increased dairy cow mortality on United States dairy operations. J. Dairy Sci. 91:1423-1432.

Negussie, E., I. Strandén, and E. A. Mäntysaari. 2008. Genetic analysis of liability to clinical mastitis, with somatic cell score and production traits using bivariate threshold-linear and linear-linear models. Livest. Sci. 117:52-59.

Norberg, E. 2008. A genetic study of postnatal mortality in Danish Jersey heifer calves. Page 117 in Book of Abstracts of the 59th Annual Meeting of the EAAP, Vilnius, Lithuania. Wageningen Academic Publishers, Wageningen, the Netherlands.

Ortiz-Pelaez, A., D. G. Pritchard, D. U. Pfeiffer, E. Jones, P. Honeyman, and J. J. Mawdsley. 2008. Calf mortality as a welfare indicator on British cattle farms. Vet. J. 176:177-181.

Østerås, O., M. S. Gjestvang, S. Vatn, and L. Sølverød. 2007. Perinatal death in production animals in the Nordic countries-Incidence and costs. Acta Vet. Scand. 49(Suppl. 1):14. 
SAS Institute. 2008. SAS Version 9.2. SAS Institute Inc., Cary, NC. Shook, G. E. 1998. Calfhood disease: An assessment. Proc. 6th World Congr. Genet. Appl. Livest. Prod., Armidale, Australia, 23:379382 .

Sorensen, D., and D. Gianola. 2002. Likelihood, Bayesian and MCMC Methods in Quantitative Genetics. Springer-Verlag, New York, NY.

Southey, B. R., S. L. Rodriguez-Zas, and K. A. Leymaster. 2003. Discrete time survival analysis of lamb mortality in a terminal sire composite population. J. Anim. Sci. 81:1399-1405.

Svensson, C., A. Linder, and S. O. Olsson. 2006. Mortality in Swedish dairy calves and replacement heifers. J. Dairy Sci. 89:47694777 .
Team Avlsværdivurdering Dansk Kvæg. 2009. Årsstatistik Avl2008/09. http://www.lr.dk/kvaeg/diverse/aarsstat2009.pdf Accessed May 5, 2010.

Tempelman, R. J. 1998. Generalized linear mixed models in dairy cattle breeding. J. Dairy Sci. 81:1428-1444.

USDA. 2007. Dairy 2007, Part I: Reference of Dairy Cattle Health and Management Practices in the United States, 2007. http:// nahms.aphis.usda.gov/dairy/dairy07/Dairy07_dr_PartI.pdf Accessed May 5, 2010.

Wathes, D. C., J. S. Brickell, N. E. Bourne, A. Swali, and Z. Cheng. 2008. Factors influencing heifer survival and fertility on commercial dairy farms. Animal 2:1135-1143. 